\title{
Some imidazolines as inhibitors of steel corrosion in hydrochloric acid
}

\author{
A.G. Berezhnaya, ${ }^{1}{ }^{(0 *}$ V.V. Chernyavina, ${ }^{1}\left(\mathbb{D}\right.$ E.S. Khudoleeva ${ }^{2}(\mathbb{C}$ \\ and I.I. Krotkii ${ }^{1}$ \\ ${ }^{1}$ Southern Federal University, st. Bolshaya Sadovaya 105/46, 344046 Rostov-on-Don, \\ Russian Federation \\ ${ }^{2}$ NPO NIIPAV, 62 Khimikov st., 347366 Volgodonsk, Rostov region, Russian Federation \\ *E-mail: berezhnaya-aleksandra@mail.ru
}

\begin{abstract}
New imidazoline derivatives were studied as steel corrosion inhibitors in hydrochloric acid at $20-80^{\circ} \mathrm{C}$. Imidazoline derivatives were conventionally divided into two groups. In one group, namely, aminoethyllaurylimidazoline, aminoethylmyristylimidazoline, aminoethylpalmitylimidazoline, and aminoethylstearylimidazoline, the compounds differ in the length of the hydrocarbon radical. Another group included compounds that differed by a functional group: aminoethyloleylimidazoline, hydroxyethyloleylimidazoline, diethylenediaminooleylimidazoline, and bis[oleylimidazoline]ethylene. The efficiency of imidazoline derivatives was evaluated by the gravimetric method, polarization curves, and electrochemical impedance spectroscopy. Quantum-chemical calculations were performed by the Hartree-Fock method. It was found that imidazolines which differ in the length of the hydrocarbon radical are the best acid corrosion inhibitors. In the temperature range studied, they provide $92-99 \%$ protection of steel. The degree of steel protection by imidazolines of the second group varies within 80-98\%, depending on the nature of the compound and temperature. The imidazolines studied are mixedtype inhibitors. It was shown that all the inhibitors increased the effective activation energy of the corrosion process. The degree of steel surface coverage with inhibitors was estimated. At all the temperatures studied, we attempted to relate the protective effect of the inhibitors to the calculated parameters: the dipole moment, the HOMO and LUMO energies, the difference in these energies, the hardness and softness of the compounds, the total electron density on the heteroatoms, and electronegativity. A correlation between the protective effect of the additives and the dipole moment and electronegativity was identified.
\end{abstract}

Received: September 2, 2021. Published: October 8, 2021

doi: $\underline{10.17675 / 2305-6894-2021-10-4-4}$

Keywords: corrosion, imidazoline, corrosion inhibitors, mild steel, hydrochloric acid.

\section{Introduction}

The annual damage from corrosion is not only due to direct metal losses but also to the failure of parts whose strength, tightness, hardness, thermal and electrical conductivity changes due to destruction. Corrosion can be controlled using suitable methods and materials 
with high corrosion resistance. However, this leads to additional costs. It is preferable to use cheap metal materials together with a suitable protection method.

Steel is a common material. It has good mechanical and metallurgical properties, which are important for the production of various equipment items. Steel often undergoes acid treatment. Hydrochloric acid is one of the most common acids. Many industries face the challenge of protecting equipment and steel products from hydrochloric acid degradation.

The use of inhibitors is an efficient protection method. Such factors as additive concentration, $\mathrm{pH}$, nature of the acid anion and the metal, molecular structure, electron density on a functional group, size of the aromatic and aliphatic parts of the organic molecule, etc. affect the protection efficiency.

Heterocyclic organic compounds are efficient inhibitors of acid corrosion. Imidazolines belong to this class [1-14]. They are used either as components of inhibitor mixtures [1] or as separately [2-14]. The good inhibitory and adsorptive ability of imidazoline and its derivatives is attributed to the peculiarities of their structure, protonization of one of the nitrogen atoms and subsequent delocalization of electrons in the ring, the presence and length of hydrophobic radicals [2-14]. Attempts have been made to find a relationship between the protective ability of imidazolines and the specific features of their structure. The consistency of experimental results and quantum-mechanical calculations has been shown [2, 11-14].

The aim of this work was to study the protective properties of new imidazoline derivatives in the corrosion of steel in hydrochloric acid and to compare the inhibition efficiency with the data of theoretical calculations.

\section{Experimental}

In this work we used St3 steel containing $0.1-0.7 \% \mathrm{C}$ with no more than the following amounts of other elements: $0.8 \% \mathrm{Mn}, 0.4 \% \mathrm{Si}, 0.05 \% \mathrm{P}, 0.05 \% \mathrm{~S}, 0.5 \% \mathrm{Cu}, 0.3 \% \mathrm{Cr}, 0.3 \%$ $\mathrm{Ni}, 97 \% \mathrm{Fe}$. St3 steel samples in the form of plates with 5 and $1 \mathrm{~cm}^{2}$ were prepared for gravimetric and polarization measurements, respectively. For impedance measurements, $2.5 \mathrm{~cm} \times 0.3 \mathrm{~cm}$ steel plates were made. All samples were degreased in alcohol, washed with distilled water and dried with filter paper.

A 15\% hydrochloric acid working solution was used. The following corrosion inhibitors were studied:

Aminoethyloleylimidazoline (AEOI):

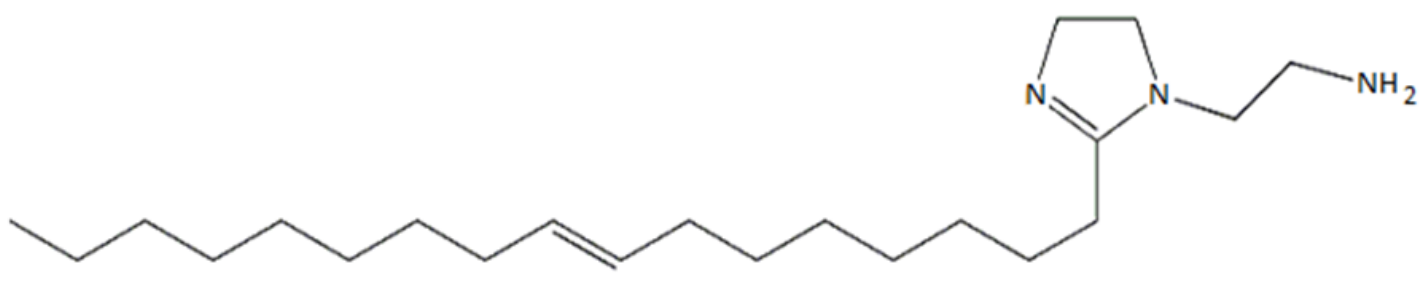


Hydroxyethyloleylimidazoline (HEOI):

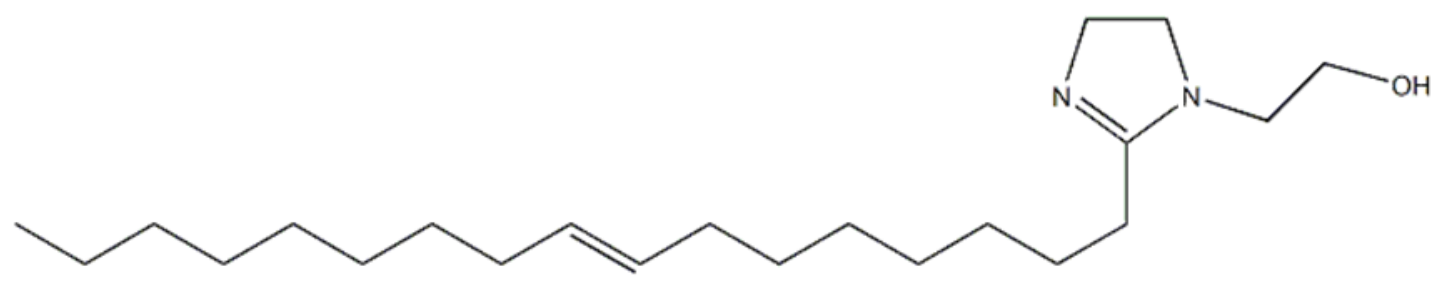

Diethylenediaminooleylimidazoline (DEDAOI):

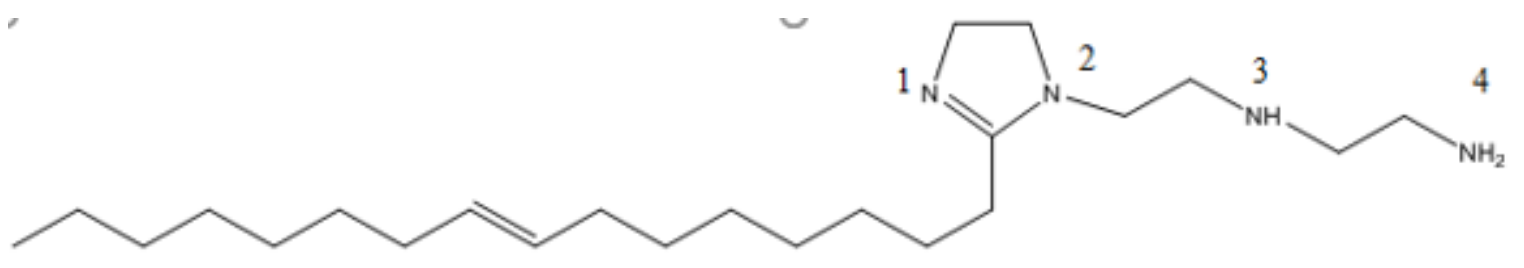

Bis(oleylimidazoline)ethylene (BOIE):

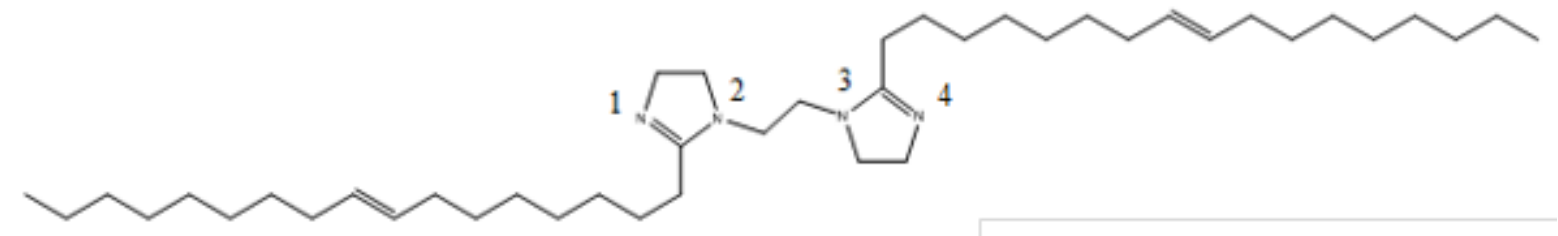

Aminoethyllaurylimidazoline (AELI):

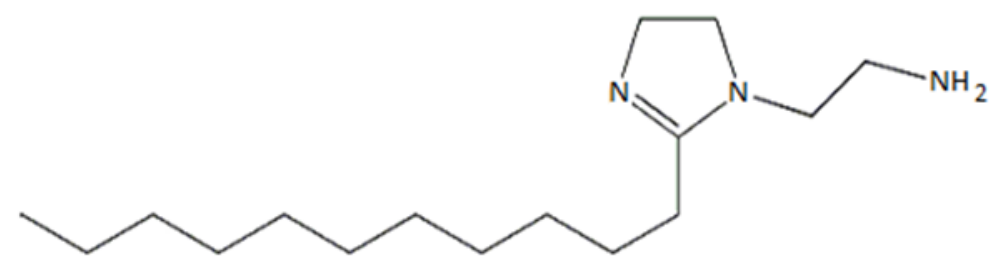

Aminoethylmyristylimidazoline (AEMI):

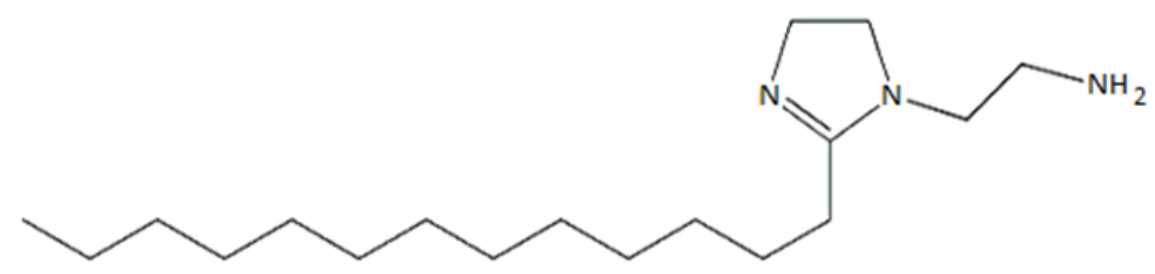


Aminoethylpalmitylimidazoline (AEPI):

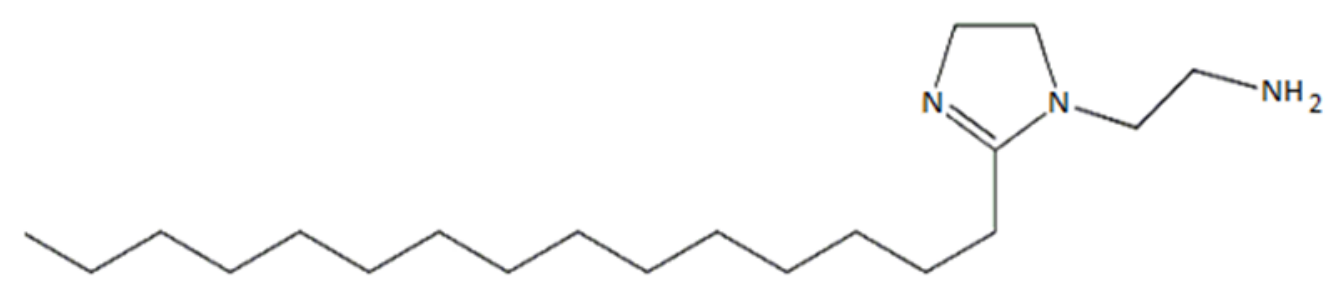

Aminoethylstearylimidazoline (AESI):

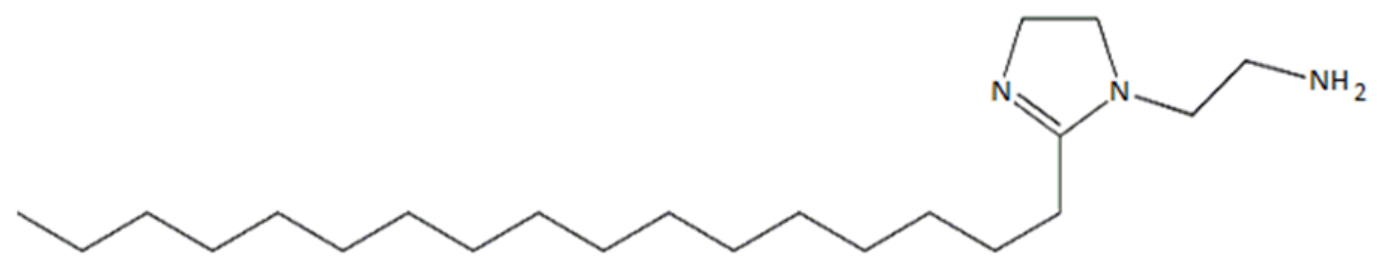

The protective effect of inhibitors was studied at concentrations of $0.01,0.1,0.2,0.5$, and $1 \mathrm{wt} . \%$ in the temperature range of $20-80^{\circ} \mathrm{C}$.

The corrosion rate $K$ was estimated from three parallel samples and calculated by equation (1), while the coefficient of inhibition $\gamma$ and the degree of protection $Z$ were calculated by equations (2) and (3):

$$
K=\frac{\Delta m}{t S}
$$

where $m=\left(m_{1}-m_{2}\right)$ in grams, $t$ is time of the experiment in hours, and $S$ is the sample area in $\mathrm{m}^{2}$.

$$
\begin{gathered}
\gamma=\frac{K_{0}}{K} \\
Z=\left[\left(K_{0}-K\right) / K_{0}\right] \cdot 100 \%
\end{gathered}
$$

where $K$ and $K_{0}$ are the corrosion rates in the presence of the inhibitor and without it, respectively, in $\mathrm{g} /\left(\mathrm{m}^{2} \cdot \mathrm{h}\right)$.

Temperature measurements were performed at $40^{\circ} \mathrm{C}, 60^{\circ} \mathrm{C}$ and $80^{\circ} \mathrm{C}$ at a fixed additive concentration of $0.1 \mathrm{wt} . \%$. Samples were loaded using a stopwatch with a time interval of 1 minute. The exposure time of samples was 3 hours at $40^{\circ} \mathrm{C}, 1$ hour at $60^{\circ} \mathrm{C}$, and 30 minutes at $80^{\circ} \mathrm{C}$.

Polarization measurements were performed on a stationary electrode on a PI-50-1 potentiostat in a three-electrode cell with separated cathode and anode spaces. A saturated silver chloride reference electrode and a platinum auxiliary electrode were used. Potentials $(E)$ are given with respect to SCE. 
Impedance measurements were performed on an impedance meter (Electrochemical Instruments, Elins, Russia) in a two-electrode cell with identical electrodes at the corrosion potential in the frequency range from $14 \mathrm{mHz}$ to $500 \mathrm{kHz}$. The results were processed using the EIS Spectrum Analyser software.

The degree of coverage of the electrode surface was calculated by the equation:

$$
\Theta=\left(C_{0}-C_{\mathrm{i}}\right) / C_{0}
$$

where $C_{0}, C_{\mathrm{i}}$ are the capacitances of the double electric layer (DEL) in the background solution and in the presence of an inhibitor, respectively.

Quantum-chemical calculations were performed within the Hartree-Fock method in the split-valence basis of Gaussian functions extended by polarization d-functions on heavy atoms $6-311 \mathrm{G}(\mathrm{d})$ in the Gaussian09 program [15]. The geometry optimization was performed without symmetry constraints; the minima on the PES were characterized by the absence of imaginary frequencies of the calculated normal vibrations.

\section{Results and Discussion}

The studied additives are molecular compounds that do not comprise functional groups carrying a charge in their molecular structure. However, the presence in the structure of a heterocycle with a delocalized bond formed by pairs of electrons located on the nitrogen atoms and multiple bonds should contribute to the high adsorption capacity and pronounced protective properties of the compounds.

The studied compounds are conventionally divided into two groups, each of which differs in small structural features (length of the hydrocarbon chain) and the presence of certain functional groups.

AELI, AEMI, AEPI, and AESI differ in the length of the hydrocarbon radical; the structure is based on the imidazoline ring and the aminoethyl radical bound to it. AEOI, HEOI, DEDAOI and BOIE are similar in the structure of the hydrocarbon radical but differ in the nature of the functional groups bound to the heterocycle. The majority of the compounds studied are poorly soluble in aqueous hydrochloric acid solution and their structures resemble those of surfactant molecules. The ring and the group bound to it act as a hydrophilic site and center of interaction with the metal surface, while the hydrocarbon chain is a hydrophobic fragment.

Based on the results obtained by the gravimetric method, it was found that all of the compounds studied behave as efficient inhibitors of steel corrosion at room temperature, Table 1. 
Table 1. Dependence of corrosion rate, inhibition coefficient and degree of protection of steel 3 on the nature of inhibiting additives and temperature.

\begin{tabular}{|c|c|c|c|c|c|c|}
\hline \multirow{2}{*}{ Additive } & \multicolumn{6}{|c|}{ Parameter, temperature } \\
\hline & $\begin{array}{c}K, \\
\mathbf{g} /\left(\mathbf{m}^{2} \cdot \mathbf{h o u r}\right)\end{array}$ & $\gamma$ & $Z, \%$ & $\begin{array}{c}K, \\
\mathbf{g} /\left(\mathbf{m}^{2} \cdot \mathbf{h o u r}\right)\end{array}$ & $\gamma$ & $Z, \%$ \\
\hline & \multicolumn{3}{|c|}{$20^{\circ} \mathrm{C}$} & \multicolumn{3}{|c|}{$40^{\circ} \mathrm{C}$} \\
\hline 0 & 12.18 & - & - & 57.20 & - & - \\
\hline AEOI & 0.22 & 55.52 & 98.20 & 1.27 & 45.16 & 97.79 \\
\hline HEOI & 0.49 & 29.31 & 96.59 & 2.62 & 21.81 & 95.42 \\
\hline DEDAOI & 0.23 & 58.60 & 98.29 & 1.27 & 45.16 & 97.79 \\
\hline BOIE & 0.24 & 42.68 & 97.66 & 5.29 & 9.19 & 89.12 \\
\hline AELI & 0.031 & 304.8 & 99.67 & 0.40 & 143.0 & 99.3 \\
\hline AEMI & 0.056 & 127.4 & 99.22 & 0.49 & 117.0 & 99.15 \\
\hline AEPI & 0.38 & 19.37 & 94.84 & 0.42 & 115.0 & 99.13 \\
\hline \multirow[t]{2}{*}{ AESI } & 0.30 & 31.87 & 96.86 & 1.98 & 24.58 & 95.93 \\
\hline & \multicolumn{3}{|c|}{$60^{\circ} \mathrm{C}$} & \multicolumn{3}{|c|}{$80^{\circ} \mathrm{C}$} \\
\hline 0 & 309.93 & - & - & 648.0 & - & - \\
\hline AEOI & 13.13 & 23.25 & 95.70 & 48.0 & 13.50 & 92.59 \\
\hline HEOI & 22.2 & 13.96 & 92.84 & 66.0 & 9.82 & 89.81 \\
\hline DEDAOI & 10.8 & 28.70 & 96.52 & 37.2 & 17.42 & 94.26 \\
\hline BOIE & 34.0 & 5.41 & 81.53 & 128.27 & 5.17 & 80.67 \\
\hline AELI & 6.93 & 44.7 & 97.76 & 26.93 & 24.06 & 95.84 \\
\hline AEMI & 11.27 & 27.51 & 96.36 & 51.20 & 12.66 & 92.10 \\
\hline AEPI & 4.0 & 46.02 & 97.83 & 37.73 & 17.58 & 94.31 \\
\hline AESI & 4.73 & 38.39 & 97.43 & 32.93 & 20.15 & 95.04 \\
\hline
\end{tabular}

An increase in temperature leads to an increase in the corrosion rate and a change in the protective properties of additives. The greatest efficiency is more often shown by AELI, AEMI, and AEPI.

The availability of data on corrosion rates at various temperatures makes it possible to determine the effective activation energy of the corrosion process in the pure acid and in the presence of the additives. The values of effective corrosion activation energy $\left(E_{\mathrm{a}}\right)$ and correlation coefficients $(R)$ of linear Arrhenius plots are presented in Table 2.

The effective activation energy of the process in the presence of the additives is significantly higher than in the pure acid solution. The highest $E_{\mathrm{a}}$ values are observed for 
AELI and AEMI. Figure 1 shows the polarization curves obtained on steel in hydrochloric acid solution without and in the presence of the additives.

Table 2. Values of effective activation energy of the corrosion process and correlation coefficients of linear plots.

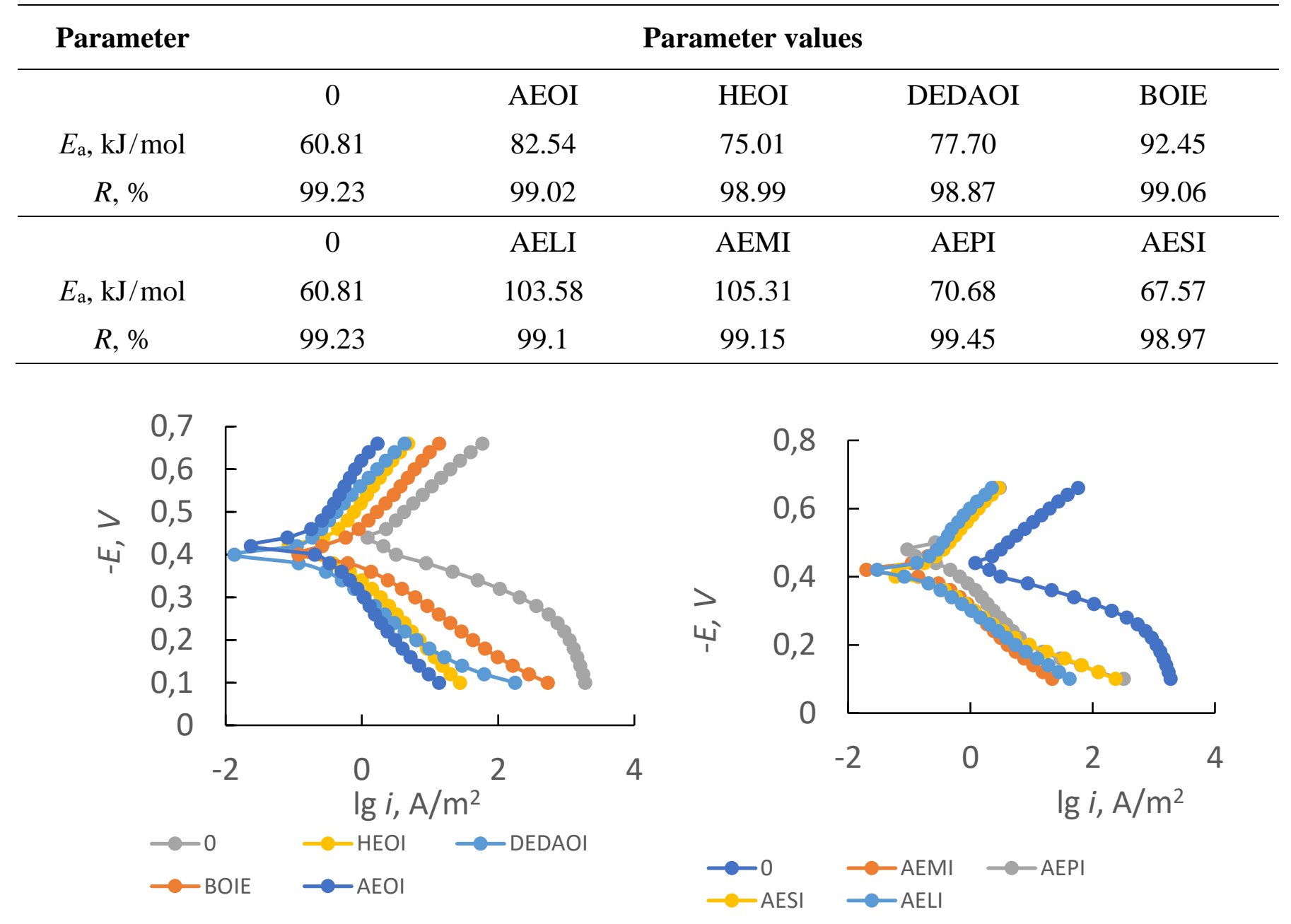

Figure 1. Polarization curves of steel 3 in $15 \%$ hydrochloric acid without (0) and in the presence of additives.

The compounds studied reduce the rates of both partial reactions of the corrosion process and are mixed-type inhibitors.

Impedance measurements show that the additives studied are quite well adsorbed on the steel surface. They block the areas where the corrosion process can occur. The Nyquist plots for the two groups of compounds and 15\% hydrochloric acid solution are shown in Figure 2. 

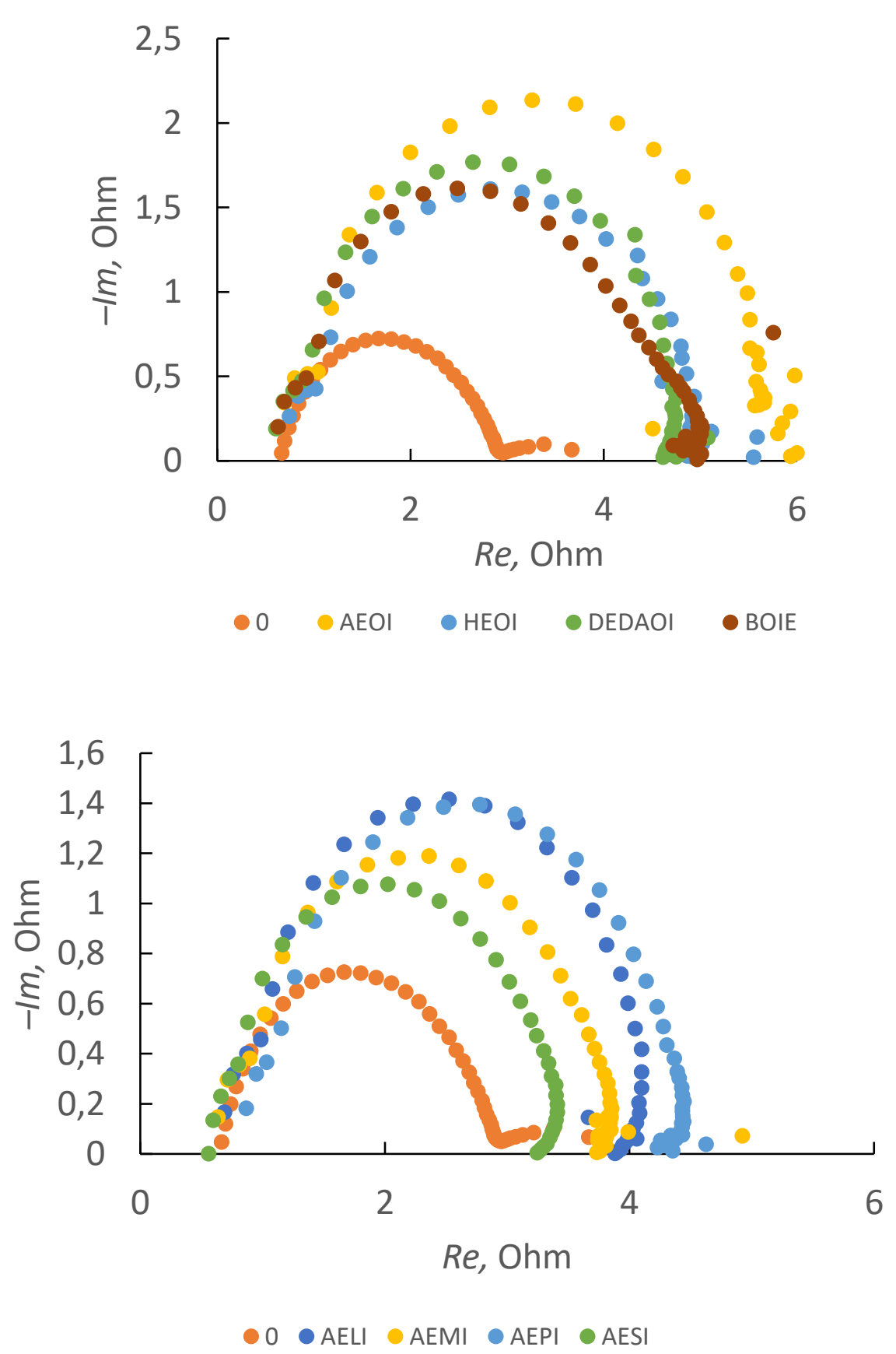

Figure 2. Nyquist diagrams on the steel electrode in hydrochloric acid solutions of $15 \%$ in the presence of individual compounds

The large values of resistance and radius of the hodographs obtained in the presence of additives in the solution indicate their inhibitory effect.

The data obtained are simulated by the following equivalent circuit: 


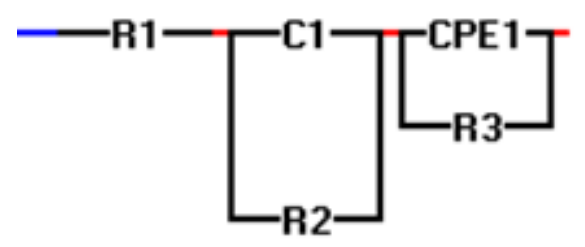

The error of the calculated parameters of the equivalent scheme for the hydrochloric acid solution without and in the presence of the additives was 5-10\%. The calculated values of the degree of coverage of the steel surface with the inhibitors are presented in Table 3.

Table 3. Degree of coverage $(\theta)$ of steel surface with the additives.

Value of $\theta$ in $15 \% \mathrm{HCl}$ with the additives

\begin{tabular}{cccccccc}
\hline AEOI & HEOI & DEDAOI & BOIE & AELI & AEMI & AEPI & AESI \\
0.50 & 0.60 & 0.70 & 0.71 & 0.58 & 0.50 & 0.80 & 0.71 \\
\hline
\end{tabular}

The values of the degree of coverage are smaller than the degree of protection (Tables 1,3), suggesting the activation-blocking mechanism of action of the inhibitors.

Some parameters of the molecules in question obtained by quantum mechanical calculations, namely, the dipole moment $(\mu)$, the energies of the highest occupied $\left(E_{\mathrm{HOMO}}\right)$ and lowest unoccupied ( $\left.E_{\mathrm{LUMO}}\right)$ orbitals, and the electron density on the heteroatoms, are presented in Table 4.

Table 4. Calculated parameters of molecules.

\begin{tabular}{|c|c|c|c|c|c|c|c|}
\hline \multirow{2}{*}{ Compound } & \multirow{2}{*}{$\mu, \mathrm{D}$} & \multirow{2}{*}{$\begin{array}{c}-E_{\text {номо }} \\
\mathrm{eV}\end{array}$} & \multirow{2}{*}{$\begin{array}{l}E_{\text {LUMO, }} \\
\text { eV }\end{array}$} & \multicolumn{4}{|c|}{ Electron density (ED) } \\
\hline & & & & N1 & $\mathrm{N} 2$ & N3 & $\mathrm{N} 4$ \\
\hline AEOI & 3.176 & 8.8835 & 3.8728 & -0.435 & -0.513 & -0.839 & - \\
\hline HEOI & 3.1475 & 8.9570 & 3.9813 & -0.433 & -0.517 & - & - \\
\hline DEDAOI & 4.0576 & 8.5292 & 3.8820 & -0.446 & -0.524 & -0.640 & -0.835 \\
\hline BOIE & 1.6595 & 8.7649 & 3.5810 & -0.431 & -0.516 & -0.528 & -0.441 \\
\hline AELI & 3.1799 & 8.8800 & 3.8785 & -0.435 & -0.513 & -0.839 & - \\
\hline AEMI & 3.1792 & 8.8794 & 3.8790 & -0.435 & -0.513 & -0.839 & - \\
\hline AEPI & 3.1788 & 8.8789 & 3.8796 & -0.435 & -0.513 & -0.839 & - \\
\hline AESI & 3.1786 & 8.8783 & 3.8801 & -0.435 & -0.513 & -0.839 & - \\
\hline
\end{tabular}

The data in Table 4 show that the second group of compounds that differ in the length of the hydrocarbon radical, have almost identical calculated parameters. There are slight differences only in the dipole moment, as well as in the $E_{\mathrm{HOMO}}$ and $E_{\mathrm{LUMO}}$. Different values 
of the parameters are observed in the first group of compounds that differ in the functional group bound to the heterocycle (AEOI, HEOI, DEDAOI and BOIE). Correlations of the efficiency of compounds with such calculated characteristics as the dipole moment $(\mu)$, sum of electron densities on the heteroatoms (ED) [4, 13], electronegativity $(\chi), E_{\mathrm{HOMO}}-E_{\mathrm{LUMO}}$ energy difference $(\Delta E)$, hardness $(\eta)$, and softness $(\sigma)$ were reported $[16,17]$.

The correlation coefficients of linear plots of the protective effect of additives, calculated parameters, or characteristics derived from them $(\chi, \Sigma \mathrm{ED}, \Delta \mathrm{E}, \eta$ and $\sigma)$ are presented in Table 5.

Table 5. Correlation coefficients of linear plots as a function of temperature.

\begin{tabular}{ccccc}
\hline \multirow{2}{*}{ Dependence } & \multicolumn{5}{c}{ Value (\%) for temperature $\boldsymbol{t},{ }^{\circ} \mathbf{C}$} \\
\cline { 2 - 5 } & $\mathbf{2 0}$ & $\mathbf{4 0}$ & $\mathbf{6 0}$ & $\mathbf{8 0}$ \\
\hline$\gamma-\mu$ & 42.4 & 85.1 & 93.3 & 95.2 \\
$\gamma-\chi$ & 50.0 & 72.8 & 86.6 & 91.1 \\
$\gamma-\Sigma \mathrm{ED}$ & 87.9 & 42.7 & 46.1 & 46.2 \\
$\gamma-\Delta \mathrm{E}$ & 50.9 & 26.6 & 7.5 & 5.7 \\
$\gamma-\eta$ & 50.9 & 13.4 & 7.5 & 5.7 \\
$\gamma-\sigma$ & 50.0 & 14.0 & 8.3 & 6.3 \\
\hline$\gamma-\mu$ & & \multicolumn{4}{c}{ Second group } \\
\hline$\gamma-\chi$ & 97.6 & 77.6 & 9.2 & 40.2 \\
\hline
\end{tabular}

As one can see from Table 5, the first group of compounds demonstrates correlations of the dipole moment and electronegativity with the protection effect. As the temperature increases, the correlations improve. There is no correlation with the other parameters. In the second group of compounds, there is also a correlation of the protective effect with the dipole moment and electronegativity at temperatures below $40^{\circ} \mathrm{C}$.

It should be noted that the compounds of the second group, which have almost identical calculated parameters, different quite significantly in the protective effect, Tables 1, 5. As mentioned earlier, AELI and AEMI are more efficient against the corrosion of steel at temperatures below $40^{\circ} \mathrm{C}$, while AELI, AEPI and AESI are more efficient at high temperatures. No less interesting is a comparison of the protective effect of AEOI and AESI that differ in the number of hydrogen atoms in the hydrocarbon radical, Table 1. In fact, AEOI which has a double bond is more efficient at temperatures below $40^{\circ} \mathrm{C}$, whereas at high temperatures its protective effect is lower than that of AESI. 


\section{Conclusion}

Thus, the imidazoline derivatives studied are inhibitors of steel corrosion in hydrochloric acid at $20-80^{\circ} \mathrm{C}$. Compounds differing in the length of the hydrocarbon radical (AELI, AEMI, AEPI, AESI) are more efficient than imidazolines with various functional groups (AEOI, HEOI, DEDAOI, BOIE). All the additives increase the activation energy of the corrosion process and are mixed-type inhibitors. Some calculated parameters of the molecules (dipole moment and electronegativity) are in good correlation with the protective action of the compounds studied.

\section{References}

1. M.D. Plotnikova and A.B. Shein, Corrosion inhibition of mild steels in acid and neutral media, Nauchn. Dokl. Vyssh. Shk., Khim. Khim. Tekhnol. (Proceedings of higher educational institutions. Chemistry and chemical technology), 2013, 56, no. 3, 35-40 (in Russian).

2. Ya.V. Ivshin, O.V. Ugryumov and O.A. Varnavskaya, Corrosion inhibitors based on heterocycloc amines. Effect of molecular structure on the prospective properties, Vestn. Tekhnol. Univ. (Technological university proceedings), 2015, 18, no. 2, 77-80 (in Russian).

3. M.A. Quraishi, M.Z.A. Rafiquee, S. Khan and N. Saxena, Corrosion inhibition of aluminium in acid solutions by some imidazoline derivatives, J. Appl. Electrochem., 2007, 37, no. 10, 1153-1162. doi: 10.1007/s10800-007-9379-0

4. D.-Q. Zhang, L.-X. Gao, G.-D. Zhou and K.Y. Lee, Undecyl substitution in imidazole and its action on corrosion inhibition of copper in aerated acidic chloride media, Acta Chim. Slov., 2007, 57, no. 2, 497-304. doi: 10.1007/s10800-007-9401-6

5. P.S. Fakhretdinov, I.Yu. Golubev, R.F. Khamidullin and G.V. Romanov, Novel imidazolinium compounds based on hydroxyethylated alkylphenols as inhibitors of acid corrosion, Vestn. Kazan. Tekhnol. Univ. (Proceedings of Kazan University), 2010, no. 1, 280-287 (in Russian).

6. V. Jovancicevic, S. Ramachandran and P. Prince, Inhibition of Carbon Dioxide Corrosion of Mild Steel by Imidazolines and Their Precursors, Corrosion, 55, no. 5, 449-455. doi: $10.5006 / 1.3284006$

7. H.B. Ouici, O. Benali, Y. Harek, S.S. Al-Deyab, L. Larabi and B. Hammouti, Influence of the 2-Mercapto-1-Methyl Imidazole (MMI) on the Corrosion Inhibition of Mild Steel in 5\% HCl, Int. J. Electrochem. Sci., 2012, 7, 2304-2319. doi: 10.1007/s11164-012$\underline{0797-1}$

8. P.C. Okafor, X. Liu and Y.G. Zheng, Corrosion inhibition of mild steel by ethylamino imidazoline derivative in $\mathrm{CO}_{2}$-saturated solution, Corros. Sci., 2009, 51, 761-768. doi: $\underline{10.17675 / 2305-6894-2018-7-3-3}$ 
9. I.A. Aiad, A.A. Hafiz, M.Y. El-Awady and A.O. Habib, Some Imidazoline Derivatives as Corrosion Inhibitors, J. Surfactants Deterg., 2010, 13, 247-254. doi: 10.1007/s11743$\underline{009-1168-9}$

10. L. Bechki, A. Lounes, K. Chouirfat, M.K. Bechki and M. Kadri, Study of the Corrosion Inhibitor of Steel in the Medium Acid in Different Concentrations of Imidazole, J. Environ. Anal. Chem., 2015, 2, no. 6. doi: 10.4172/2380-2391.1000167

11. L.M. Rodriguez-Valdez, W. Villamisar, M. Casales, J.G. Gonza'lez-Rodriguez, A. Martinez-Villafane, L. Martinez and D. Glossman-Mitnik, Computational simulations of the molecular structure and corrosion properties of amidoethyl, aminoethyl and hydroxyethyl imidazolines inhibitors, Corros. Sci., 2006, 48, 40534064. doi: $10.1016 /$ j.corsci.2006.05.036

12. J. Cruz, R. Martınez, J. Genesca and E. Garcia-Ochoa, Experimental and theoretical study of 1-(2-ethylamino)-2-methylimidazoline as an inhibitor of carbon steel corrosion in acid media, J. Electroanal. Chem., 2004, 566, 111-121. doi: 10.1016/j.jelechem.2003.11.018

13. D. Wang, S. Li, Y. Ying, M. Wang, H. Xiao and Z. Chen, Theoretical and Experimental Studies of Structure and Inhibition Efficiency of Imidazoline Derivatives, Corros. Sci., 1999, 41, no. 10, 1911-1919. doi: 10.1016/S0010-938X(99)00027-X

14. S. Ramachandran, B.L. Tsai, M. Blanco, H. Chen, Y. Tang and W.A. Goddard, SelfAssembled Monolayer Mechanism for Corrosion Inhibition of Iron by Imidazolines, Langmuir, 1996, 12, 6419-6428. Link

15. M.J. Frisch, G.W. Trucks, H.B. Schlegel, G.E. Scuseria, M.A. Robb, J.R. Cheeseman, G. Scalmani, V. Barone, B. Mennucci, G.A. Petersson, H. Nakatsuji, M. Caricato, X. Li, H.P. Hratchian, A.F. Izmaylov, J. Bloino, G. Zheng, J.L. Sonnenberg, M. Hada, M. Ehara, K. Toyota， R. Fukuda，J. Hasegawa， M. Ishida, T. Nakajima, Y. Honda, O. Kitao, H. Nakai, T. Vreven, J.A. Montgomery, J.E. Peralta Jr, F. Ogliaro, M. Bearpark， J.J. Heyd， E. Brothers， K.N. Kudin， V.N. Staroverov， R. Kobayashi, J. Normand, K. Raghavachari, A. Rendell, J.C. Burant, S.S. Iyengar, J. Tomasi, M. Cossi, N. Rega, J.M. Millam, M. Klene, J.E. Knox, J.B. Cross, V. Bakken, C. Adamo, J. Jaramillo, R. Gomperts, R.E. Stratmann, O. Yazyev, A.J. Austin, R. Cammi, C. Pomelli, J.W. Ochterski, R.L. Martin, K. Morokuma, V.G. Zakrzewski, G.A. Voth, P. Salvador, J.J. Dannenberg, S. Dapprich, A.D. Daniels, O. Farkas, J.B. Foresman, J.V. Ortiz, J. Cioslowski and D.J. Fox, Gaussian 09, Revision A.02, Gaussian, Inc., Wallingford CT, 2009.

16. G. Bereket, E. Hur and C. Ogretir, Quantum chemical studies on some imidazole derivatives as corrosion inhibitors for iron in acidic medium, J. Mol. Struct., 2002, 578, 79-88. doi: $\underline{10.1016 / \mathrm{S} 0166-1280(01) 00684-4}$ 
17. H. Rahmani, F. El-Hajjaji, A. El Hallaoui, M. Taleb, Z. Rais, M. El Azzouzi, B. Labriti, K. Ismaily Alaoui and B. Hammouti, Experimental, quantum chemical studies of oxazole derivatives as corrosion inhibitors on mild steel in molar hydrochloric acid medium, Int. J. Corros. Scale Inhib., 2018, 7, no. 4, 509-527. doi: 10.17675/2305-6894$\underline{2018-7-4-3}$ 